\title{
Improvement in the blastocyst quality and efficiency of putative embryonic stem cell line derivation from porcine embryos produced in vitro using a novel culturing system
}

\author{
SEUNG A.CHEONG* , EUNHYE KIM* ${ }^{*}$, SEONG-SUNG KWAK, YUBYEOL JEON and SANG-HWAN HYUN \\ Laboratory of Veterinary Embryology and Biotechnology, College of Veterinary Medicine, \\ Chungbuk National University, Cheongju, Chungbuk 361-763, Republic of Korea
}

Received May 28, 2014; Accepted March 26, 2015

DOI: $10.3892 / \mathrm{mmr} .2015 .3634$

\begin{abstract}
Porcine embryonic stem cells (pESCs) have great potential for application in translational biomedical research, including xenotransplantation and disease models. Obtaining high-quality blastocysts is the most important factor in the isolation and colonization of primary ESCs and the establishment of ESC lines. In pigs, in vitro-derived blastocysts have a limited cell number compared to in vivo-derived blastocysts and show an indefinite inner cell mass, which may result in failure to establish pESC lines. In the present study, the effects of resveratrol (RES), granulocyte-macrophage colony stimulating factor (GM-CSF) and $\beta$-mercaptoethanol ( $\beta$-ME) on the quality of blastocysts and the efficiency of colony derivation were investigated for the establishment of ESCs. A novel culturing system was developed in which $2 \mu \mathrm{M}$ RES was added to the oocyte in vitro maturation (IVM) medium, and $10 \mathrm{ng} / \mathrm{ml} \mathrm{pGM}-\mathrm{CSF}$ and $10 \mu \mathrm{M} \beta$-ME were added to embryo in vitro culture (IVC) medium. This novel system showed significantly more parthenogenetic activation (PA) blastocysts $(54.5 \pm 1.8 \%$ vs. $43.4 \pm 1.2 \% ; \mathrm{P}<0.05)$ and in vitro fertilization (IVF) blastocysts $(36.9 \pm 3.3 \%$ vs. $26.2 \pm 2.9 \%$; $\mathrm{P}<0.06)$ at day seven as compared with that in the control system. The PA and IVF blastocysts from the novel system showed a significantly greater hatching rate $(\mathrm{P}<0.05)$ and greater cell numbers $(55.1 \pm 2.0$ vs. $45.6 \pm 2.0 ; \mathrm{P}<0.05$ and $78.9 \pm 6.8$ vs. $58.5 \pm 7.2$; $\mathrm{P}<0.06$, for PA and IVF, respectively) at day seven compared to that in the control system. After seeding on feeder cells, the
\end{abstract}

Correspondence to: Professor Sang-Hwan Hyun, Laboratory of Veterinary Embryology and Biotechnology, College of Veterinary Medicine, Chungbuk National University, 52 Naesudong-ro, Cheongju, Chungbuk 361-763, Republic of Korea

E-mail: shhyun@cbu.ac.kr

*Contributed equally

Key words: in vitro maturation, in vitro culture, porcine embryonic stem cells, resveratrol, porcine granulocyte-macrophage colony stimulating factor, $\beta$-mercaptoethanol
PA blastocysts produced by the novel system showed a significantly increased rate of attachment $(28.8 \pm 3.9 \%$ vs. $17.2 \pm 2.4 \%$; $\mathrm{P}<0.062)$. Finally, two putative pESC lines from PA embryos produced by the novel system and one by the control system were established. In conclusion, the novel system improved blastocyst quality and increased the derivation efficiency of putative pESC lines from porcine PA and IVF embryos produced in vitro.

\section{Introduction}

Embryonic stem cell (ESC) lines are able to renew without differentiation and exhibit pluripotency in vitro under optimal conditions over a long period of time (1). Since ESC lines were first established from the mouse inner cell mass (ICM) in 1981 (2), attempts to isolate human ESCs have been successfully performed (1). In addition, numerous studies have attempted to establish ESC lines from other species, including sheep (3), hamster (4), mink (5), rabbit (6), pig (7), cattle (8), rat (9) and horse (10). However, to date, authentic ESCs have only been established from the rat $(11,12)$.

Compared to other animals, pigs are a favored animal model for translational research regarding humans due to their similarities in size and physiology (13). There is also great potential for using genetically modified pigs as organ donors for xenotransplantation and as a model for human diseases (14). Putative porcine ESC (pESC) lines were first established in 1990 using porcine blastocysts expanded in vivo for 7-9 days (15). Although embryos produced in vivo are of high quality compared to embryos produced in vitro, this approach is more expensive and laborious. Therefore, it would be economically desirable to use blastocysts created in vitro. However, to date, only few putative ESC lines have been established in farm animals from material produced in vitro (16).

The production of porcine blastocysts in vitro was first attempted in 2000 (17). However, it has remained challenging to establish pESCs from porcine blastocysts produced in vitro, as there is often no obvious ICM, or only a few cells are present in porcine embryos (16). One of the reasons for this difficulty is an incomplete in vitro production system for porcine embryos compared to the in vivo environment. Therefore, numerous attempts have been made to improve the conditions of in vitro 
systems to the level of what occurs in vivo. Traditionally, M199 has been used as a common medium for in vitro maturation (IVM) in most laboratories (18). Funahashi et al $(19,20)$ found that the cytoplasmic maturation of porcine oocytes is significantly affected by the maturation medium. Supplementation of the maturation medium with cystein enhances the amount of glutathione in porcine oocytes and improves the formation of the maternal pronucleus (MPN) after sperm penetration (21). For in vitro culture (IVC), porcine zygote medium-5 (PZM5) had been developed by Yoshioka et al (22) and has been used in numerous studies (23) as a replacement for porcine zygote medium-3 (PZM3), the traditional medium for IVC (24). However, the developmental competence of in vitro culture systems was still below that observed in vivo.

The aim of the present study was to examine the effects of resveratrol (RES), granulocyte-macrophage colony stimulating factor (GM-CSF) and $\beta$-mercaptoethanol $(\beta-\mathrm{ME})$ on the quality of blastocysts and the efficiency of colony derivation in the establishment of ESCs. To obtain porcine blastocysts derived in vitro, an in vitro fertilization (IVF) and parthenogenetic activation (PA) were performed. The control system used M199 media for IVM and PZM3 for IVC. By contrast, the novel system used M199 media with $2 \mu \mathrm{M}$ RES for IVM and PZM5 with $2 \mu \mathrm{M}$ RES, $10 \mathrm{ng} / \mathrm{ml}$ of porcine GM-CSF (pGM-CSF) and $10 \mu \mathrm{M} \beta$-ME for IVC, while the control system had no additives. To characterize putative pESCs from PA embryos derived by the novel and control systems, various parameters were compared, including typical morphology, alkaline phosphatase (AP) activity analysis, embryoid body (EB) formation and gene expression analysis (OCT4, SOX2, Nanog, NESTIN, BLBP, C.actin, SOX17, GATA6 and PECAM).

\section{Materials and methods}

Chemicals. All chemicals were purchased from Sigma-Aldrich Chemical Company (St. Louis, MO, USA) unless stated otherwise.

In vitro maturation (IVM) of porcine oocytes. Ovaries of gilts were collected from a commercial abattoir. Porcine cumulus-oocyte complexes (COCs) with follicular fluid were aspirated from 3- to 6-mm antral follicles using a $10-\mathrm{ml}$ syringe and an 18-gauge needle. COCs were recovered under a stereoscopic microscope (SZ51; Olympus, Tokyo, Japan) and washed in 4-(2-hydroxyethyl)-1-piperazineethanesulfonic acid-buffered Tyrode's medium containing $0.05 \%$ (w/v) polyvinyl alcohol (TLH-PVA). Subsequently, 60-70 COCs from the control group were cultured in a four-well dish (Nunc, Roskilde, Denmark) containing $500 \mu \mathrm{l}$ tissue culture medium 199 (Invitrogen Life Technologies, Carlsbad, CA, USA) supplemented with $26 \mathrm{mM}$ sodium bicarbonate, $0.91 \mathrm{mM}$ sodium pyruvate, $0.57 \mathrm{mM}$ cysteine, $10 \mathrm{ng} / \mathrm{ml}$ epidermal growth factor, $0.5 \mathrm{IU} / \mathrm{ml}$ porcine luteinizing hormone, 0.5 $\mathrm{IU} / \mathrm{ml}$ porcine follicle-stimulating hormone, $10 \%(\mathrm{v} / \mathrm{v}) \mathrm{pFF}$, $75 \mu \mathrm{g} / \mathrm{ml}$ penicillin- $\mathrm{G}$ and $50 \mu \mathrm{g} / \mathrm{ml}$ streptomycin at $39^{\circ} \mathrm{C}$ under $5 \% \mathrm{CO}_{2}$ in air. After $22 \mathrm{~h}, \mathrm{COCs}$ were replaced in the same medium without hormone supplements and then cultured for $20 \mathrm{~h}$ under the same conditions. COCs from the treatment group were cultured in the same medium with $2 \mu \mathrm{M}$ RES. After $42 \mathrm{~h}$ of IVM, matured oocytes were selected and used for production of IVF and PA embryos. In the control system, M199 media was used for IVM, while the novel system used M199 media with $2 \mu \mathrm{M}$ RES for IVM.

In vitro fertilization (IVF) of porcine oocytes. For IVF, liquid semen supplied weekly from the Veterinary Service Laboratory (Department of Livestock Research, Yong-in, Korea) and was maintained at $17^{\circ} \mathrm{C}$ for 5 days prior to use. After IVM, a denuded oocyte was co-incubated with sperm for $20 \mathrm{~min}$ at $39^{\circ} \mathrm{C}$ in a humidified atmosphere of $5 \% \mathrm{CO}_{2}$ and $95 \%$ air. After co-incubation, attached sperm was removed from the zona pellucida $(\mathrm{ZP})$ by pipetting. Oocytes were then washed three times and incubated in modified Tris-buffered medium (mTBM) without sperm for $5-6 \mathrm{~h}$ at $39^{\circ} \mathrm{C}$ in a humidified atmosphere of $5 \% \mathrm{CO}_{2}$ and $95 \%$ air. Thereafter, zygotes were washed three times with embryo culture medium and cultured in PZM3 or modified PZM5. The control system used PZM3 for IVC, while the novel system used PZM5 with $2 \mu \mathrm{M}$ RES, $10 \mathrm{ng} / \mathrm{ml} \mathrm{pGM}-\mathrm{CSF}$ and $10 \mu \mathrm{M} \beta$-ME for IVC. The embryos with culture medium were covered with pre-warmed mineral oil and incubated at $39^{\circ} \mathrm{C}$ for seven days under a humidified atmosphere of $5 \% \mathrm{O}_{2}, 5 \% \mathrm{CO}_{2}$ and $90 \% \mathrm{~N}_{2}$.

Parthenogenetic activation (PA) of oocytes. Oocytes were activated with two pulses of $120 \mathrm{~V} / \mathrm{mm}$ of DC for $60 \mu \mathrm{s}$ in $280 \mathrm{mM}$ mannitol solution containing $0.01 \mathrm{mM} \mathrm{CaCl}_{2}$ and $0.05 \mathrm{mM} \mathrm{MgCl}_{2}$. For PA, oocytes that reached MII stage after $42 \mathrm{~h}$ of IVM were activated. Following electrical activation, PA embryos were treated with $2 \mathrm{mM}$ 6-dimethylaminopurine, $0.4 \mu \mathrm{g} / \mathrm{ml}$ demecolcine and $5 \mu \mathrm{g} / \mathrm{ml}$ of cytochalasin B in PZM3 for $4 \mathrm{~h}$. PA embryos were then washed three times in fresh IVC medium, transferred into $30-\mu 1$ microdrops of IVC medium in mineral oil and then cultured at $39^{\circ} \mathrm{C}$ in a humidified atmosphere of $5 \% \mathrm{O}_{2}, 5 \% \mathrm{CO}_{2}$ and $90 \% \mathrm{~N}_{2}$ for seven days. The control system used PZM3 for IVC, while the novel system used PZM5 with $2 \mu \mathrm{M}$ RES, $10 \mathrm{ng} / \mathrm{ml}$ pGM-CSF and $10 \mu \mathrm{M}$ $\beta-\mathrm{ME}$.

Embryo evaluation and total cell count. Embryos were evaluated for cleavage under a stereomicroscope on day two. Blastocyst formation on day seven after PA or IVF was classified according to the degree of expansion and hatching status: Early blastocyst (small blastocyst with a blastocoel equal to or less than half of the embryo volume), expanded blastocyst (large blastocyst with a blastocoel greater than half of the embryo volume or blastocyst with a blastocoel completely filling the embryo) and hatched blastocyst (hatching or already hatched blastocyst). To determine the total number of blastocysts on day seven, all blastocysts were collected, washed in phosphate-buffered saline (PBS) containing $1 \%(\mathrm{w} / \mathrm{v})$ bovine serum albumin (BSA) and stained with $10 \mu \mathrm{g} / \mathrm{ml}$ of Hoechst-33342 for $5 \mathrm{~min}$. After washing again in PBS-BSA, embryos were fixed in PBS containing $4 \%$ paraformaldehyde. Then, the blastocysts were mounted on glass slides in a drop of glycerol, covered gently with a cover slip and observed under a fluorescence microscope (Nikon Corp., Tokyo, Japan). This study was approved by the committee on the ethics committee on the ethics of animal experiments (Chungbuk National Unviersity, Cheongju, Republic of Korea; Permit no. CBNUA-584-13-01). 
Table I. Primer sequences for gene expression analysis.

\begin{tabular}{|c|c|c|c|}
\hline Gene & Primer sequences $\left(5^{\prime}-3^{\prime}\right)$ & Product size (bp) & GenBank accession number \\
\hline$C D X 2$ & $\begin{array}{l}\text { F: GGAACCTGTGCGAGTGGATG } \\
\text { R: GCTCGGCCTTTCTCCGAATG }\end{array}$ & 168 & CK_458871 \\
\hline$B A X$ & $\begin{array}{l}\text { F: TGCCTCAGGATGCATCTACC } \\
\text { R: AAGTAGAAAAGCGCGACCAC }\end{array}$ & 199 & XM_003127290 \\
\hline$B A K$ & $\begin{array}{l}\text { F: GCGGAAAACGCCTATGAGTA } \\
\text { R: GCAGTGATGCAGCATGAAGT }\end{array}$ & 189 & XM_001928147 \\
\hline$B c l-2$ & $\begin{array}{l}\text { F: AGGGCATTCAGTGACCTGAC } \\
\text { R: CGATCCGACTCACCAATACC }\end{array}$ & 193 & NM_214285 \\
\hline Sirtl & $\begin{array}{l}\text { F: GGACAGTTCCAGCCATCTCT } \\
\text { R: CCTCGTACAGCTTCACAGTCA }\end{array}$ & 200 & NM_001145750 \\
\hline OCT4 & $\begin{array}{l}\text { F: GCGGACAAGTATCGAGAACC } \\
\text { R: CCTCAAAATCCTCTCGTTGC }\end{array}$ & 200 & NM_001113060 \\
\hline Nanog & $\begin{array}{l}\text { F: AGCAACCAAACCTGGAACAG } \\
\text { R: TGGGTACCGCAGTACTTTGA }\end{array}$ & 209 & NM_001129971 \\
\hline SOX2 & $\begin{array}{l}\text { F: CTGCAGTACAACTCCATGACCA } \\
\text { R: CATGCTGATCATGTCCCGTA }\end{array}$ & 216 & NM_001123197 \\
\hline NESTIN & $\begin{array}{l}\text { F: GCCCACAATAGATTGGTATTT } \\
\text { R: AGCATCTTTACAGCGACAGTC }\end{array}$ & 201 & TC295480 \\
\hline$B L B P$ & $\begin{array}{l}\text { F: TTGGTGATGTGGTTGCTGTT } \\
\text { R: TCACATTTTCCACCTCCACA }\end{array}$ & 174 & TC241634 \\
\hline C.actin & $\begin{array}{l}\text { F: CAGGTATTGCTGATCGCATGCA } \\
\text { R: ATTTGCGG GGACGATGGA }\end{array}$ & 201 & TC270296 \\
\hline PECAM & $\begin{array}{l}\text { F: CATTTCCAA AGTCAGCAGCA } \\
\text { R: ATCATCATGCCTCCCTTCTG }\end{array}$ & 171 & TC238302 \\
\hline GATA6 & $\begin{array}{l}\text { F: CAGGAA ACG AAA ACCTAAGAGCAT } \\
\text { R: TTCTCGGGATTAGCGCTCTC }\end{array}$ & 201 & TC238300 \\
\hline SOX17 & $\begin{array}{l}\text { F: CGCACGGAGTTTGAACAATA } \\
\text { R: CAGACGTCGGGGTAGTTACAG }\end{array}$ & 167 & TC248504 \\
\hline GAPDH & $\begin{array}{l}\text { F: GTCGGTTGTGGATCTGACCT } \\
\text { R: TTGACGAAGTGGTCGTTGAG }\end{array}$ & 207 & NM_001206359 \\
\hline
\end{tabular}

Gene expression analysis of blastocysts and putative pESCs by reverse transcription quantitative polymerase chain reaction ( $R T-q P C R)$. Total RNA was extracted from blastocysts using TRIzol reagent (Invitrogen Life Technologies), according to the manufacturer's instructions. Complementary DNA (cDNA) was prepared by subjecting $0.8 \mu \mathrm{g}$ of total RNA to reverse transcription using Moloney murine leukemia virus (MMIV) reverse transcriptase (Invitrogen Life Technologies) and random primers (9-mers; Takara Bio Inc., Otsu, Japan). Then, quantitative real-time PCR was performed on MX3000P machine (Stratagene-Agilent Technologies, Waldbronn, Germany) with $1 \mu \mathrm{l}$ cDNA template added to $10 \mu \mathrm{l} 2 \mathrm{X}$ SYBR Premix Ex Taq (Takara Bio Inc.) containing specific primers. The reactions were performed over 40 cycles, and the cycling parameters were as follows: Denaturation at $95^{\circ} \mathrm{C}$ for $30 \mathrm{sec}$, annealing at $57^{\circ} \mathrm{C}$ for $30 \mathrm{sec}$ and extension at $72^{\circ} \mathrm{C}$ for $30 \mathrm{sec}$. All primer sequences are presented in Table I. The expression levels of each target gene were quantified relative to those of
GAPDH. Relative quantification was based on a comparison of threshold cycle $(\mathrm{Ct})$ at constant fluorescence intensity. Relative mRNA expression (R) was calculated using the equation, $\mathrm{R}=2-[\Delta \mathrm{Ct}$ sample- $\Delta \mathrm{Ct}$ control $]$. To determine a normalized arbitrary value for each gene, every obtained value was normalized to that of GAPDH. Experiments were repeated at least three times.

The cDNA from pESCs was amplified in a $20-\mu 1$ PCR reaction containing 10 pmol forward and reverse primers (iNtRON Biotechnology, SungNam., Korea), 2 units Taq polymerase (iNtRON Biotechnology), 10X PCR buffer (iNtRON Biotechnology), 5 pmol desoxyribonucleotide triphosphate mixtures (iNtRON Biotechnology) and template (cDNA), on a PTC-100 thermal cycler (MJ Research, Inc., Watertown, MA, USA). The PCR reactions were performed for 30 cycles with the following conditions: Denaturation for $30 \mathrm{sec}$ at $95^{\circ} \mathrm{C}$, annealing for $30 \mathrm{sec}$ at $57^{\circ} \mathrm{C}$ and extension for $30 \mathrm{sec}$ at $72^{\circ} \mathrm{C}$. The reaction products were analyzed on a $1.5 \%$ 
Table II. Effects of the novel system on embryonic development in porcine embryos following parthenogenetic activation.

\begin{tabular}{|c|c|c|c|c|}
\hline \multirow[b]{2}{*}{ Groups } & \multirow{2}{*}{$\begin{array}{c}\text { Embryos } \\
\text { cultured (n) }\end{array}$} & \multicolumn{2}{|c|}{ Embryos developed to } & \multirow{2}{*}{$\begin{array}{l}\text { Total cell number in } \\
\text { blastocysts, } \mathrm{n}(\mathrm{N})^{\mathrm{a}}\end{array}$} \\
\hline & & $\geq 2$ cells, $n(\%)$ & Blastocysts, n (\%) & \\
\hline Control & 649 & $562(86.2 \pm 0.8)^{\mathrm{b}}$ & $280(43.4 \pm 1.2)^{\mathrm{b}}$ & $45.6 \pm 2.0(34)^{\mathrm{b}}$ \\
\hline Novel system & 561 & $499(88.5 \pm 0.6)^{\mathrm{c}}$ & $313(54.5 \pm 1.8)^{\mathrm{c}}$ & $55.1 \pm 2.0(58)^{\mathrm{c}}$ \\
\hline
\end{tabular}

Values are expressed as the mean \pm standard error of the mean $(n=7) .{ }^{a} \mathrm{~N}$, number of blastocysts examined. ${ }^{\text {b,c }}$ Values with different superscripts within a column differ significantly $(\mathrm{P}<0.05)$.

Table III. Effects of the novel system on embryonic development after in vitro fertilization.

\begin{tabular}{|c|c|c|c|c|}
\hline \multirow[b]{2}{*}{ Groups } & \multirow{2}{*}{$\begin{array}{l}\text { Embryos } \\
\text { cultured (n) }\end{array}$} & \multicolumn{2}{|c|}{ Embryos developed to } & \multirow{2}{*}{$\begin{array}{l}\text { Total cell number in } \\
\text { blastocysts, } \mathrm{n}(\mathrm{N})^{\mathrm{a}}\end{array}$} \\
\hline & & $\geq 2$ cells, $\mathrm{n}(\%)$ & Blastocysts, n (\%) & \\
\hline Control & 375 & $267(70.9 \pm 1.4)$ & $94(26.2 \pm 2.9)^{\mathrm{b}}$ & $58.5 \pm 7.2(11)^{b}$ \\
\hline Novel system & 237 & $172(73.4 \pm 3.6)$ & $87(36.9 \pm 3.3)^{\mathrm{c}}$ & $78.9 \pm 6.8(18)^{\mathrm{c}}$ \\
\hline
\end{tabular}

Values are expressed as the mean \pm standard error of the mean $(n=3,4) .{ }^{a} \mathrm{~N}$, number of blastocysts examined. ${ }^{\mathrm{b}, \mathrm{c}}$ Values with different superscripts within a column differ significantly $(\mathrm{P}<0.05)$.

agarose gel (Pronadisa, Laboratorios Conda SA, Madrid, Spain) pre-stained with ethidium (Sigma-Aldrich Chemical Company, St. Louis, MO, USA). The gels were scanned by a Gel Doc 2000 apparatus (Bio-Rad Laboratories, Hercules, CA, USA) and compared to a 100-bp ladder of DNA (iNtRON Biotechnology).

Preparation of mouse embryonic fibroblasts as the feeder cell layer. The feeder cell layer was prepared from ICR mice (DBL, Eumseong, Republic of Korea) at pregnancy day 13, when the mice were sacrificed and the fetuses recovered. Fetal heads, internal organs and legs were removed, after which the remaining tissues were minced in PBS and centrifuged at $357 \mathrm{x} \mathrm{g}$ for $3 \mathrm{~min}$ at least twice until mouse embryonic fibroblasts (MEFs) were obtained. MEFs were cultured in Dulbecco's modified Eagle's medium (DMEM; Gibco-BRL, Carlsbad., CA., USA) with $10 \%$ fetal bovine serum (Gibco-BRL), 1\% non-essential amino acids (Gibco-BRL), $1 \%$ glutamine (Gibco-BRL), $0.1 \mathrm{mM} \beta$-mercaptoethanol (Gibco-BRL) and $1 \%$ antibiotics-antimycotics (Gibco-BRL) (growth medium) at $37^{\circ} \mathrm{C}$ under $5 \% \mathrm{CO}_{2}$ in air. MEFs were passaged 2-3 times and then inactivated with $10 \mu \mathrm{g} / \mathrm{ml} \mathrm{mito-}$ mycin C (Roche, Basel, Switzerland) for 2-2.5 h for use as culture pig blastocysts. Inactivated MEFs were plated at a density of $5 \times 10^{5}$ cells $/ \mathrm{ml}$ in a four-well dish coated with $0.5 \%$ gelatin in growth medium.

Derivation and culture of putative pESC lines. Stem cell culture medium consisted of low-glucose DMEM/F10 (Gibco-BRL) containing $1 \%$ non-essential amino acids, $1 \%$ glutamine, $0.1 \mathrm{mM} \beta$-mercaptoethanol and $1 \%$ antibiotics-antimycotics with $4 \mathrm{ng} / \mathrm{ml}$ basic fibroblast growth factor (Invitrogen Life Technologies) and 10\% FBS. Inactive feeder cells were replaced by stem cell culture medium $2 \mathrm{~h}$ prior to blastocyst plating. Blastocysts were removed from the zona pellucida using $0.5 \%$ protease. For plating, blastocysts were washed three times in stem cell culture medium and plated onto the feeder cell layer. The plating efficiency of primary cultures was determined by scoring the number of attached colonies after $48 \mathrm{~h}$. Medium was changed daily, and cells were passaged manually every 7-10 days under phase contrast microscopy (DMI 4000B, Leica Microsystems, Wetzlar, Germany).

AP activity detection and in vitro differentiation. After removal of the medium, pESCs were washed with PBS three times and then fixed with PBS containing 4\% paraformaldehyde for $5 \mathrm{~min}$ at room temperature. AP activity was then assayed with nitroblue tetrazolium/5-bromo-4-chloro-3-indolyl-phosphate solution (Roche). To confirm the in vitro differentiation of putative pESCs, cells were harvested and washed to remove feeder cells. Putative pESCs were transferred into DMEM supplemented with $10 \%$ FBS without bFGF for 14 days of suspension.

Statistical analysis. Statistical analyses were performed using SPSS 17.0 (SPSS, Inc., Chicago, IL, USA). Percentages and rates (e.g., cleavage, blastocyst formation and number of nuclei) were compared by one-way analysis of variance followed by Duncan's multiple range test. All values are expressed as the mean \pm standard error of the mean.

\section{Results}

Effect of the novel system on blastocyst quality. In the first set of experiments, the novel system was evaluated regarding subsequent embryonic development following PA and IVF. 
A

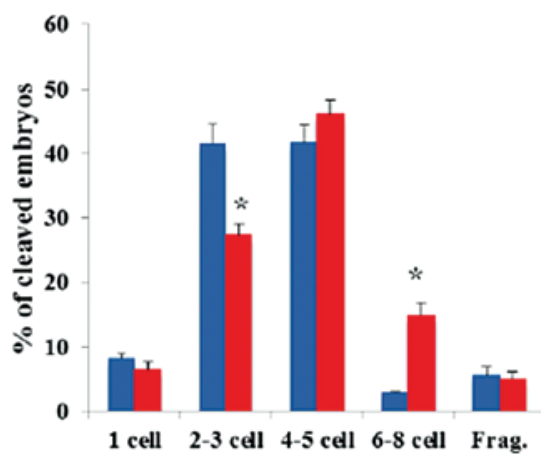

B

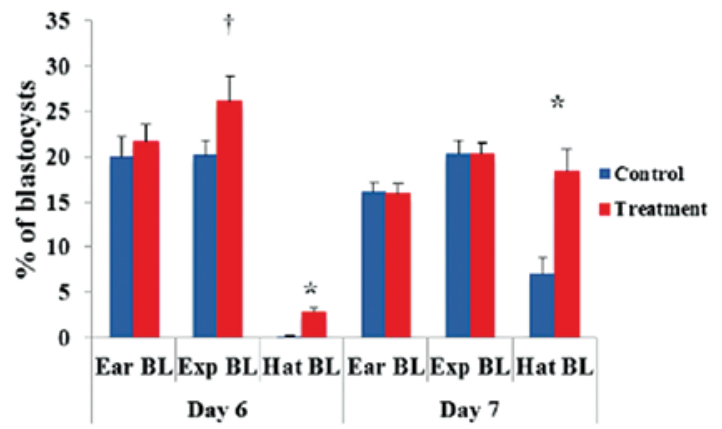

Figure 1. Effects of the novel system on the cleavage and blastocyst patterns after PA. (A) Cleavage pattern at day 2 after PA. (B) Blastocyst pattern after PA. The data are expressed as the mean \pm standard error of the mean of three replicates $\left({ }^{*} \mathrm{P}<0.05,{ }^{ } \mathrm{P}=0.074\right)$. PA, parthenogenetic activation; BL, blastocyst; Ear, early; Exp, expanded; Hat, hatched.
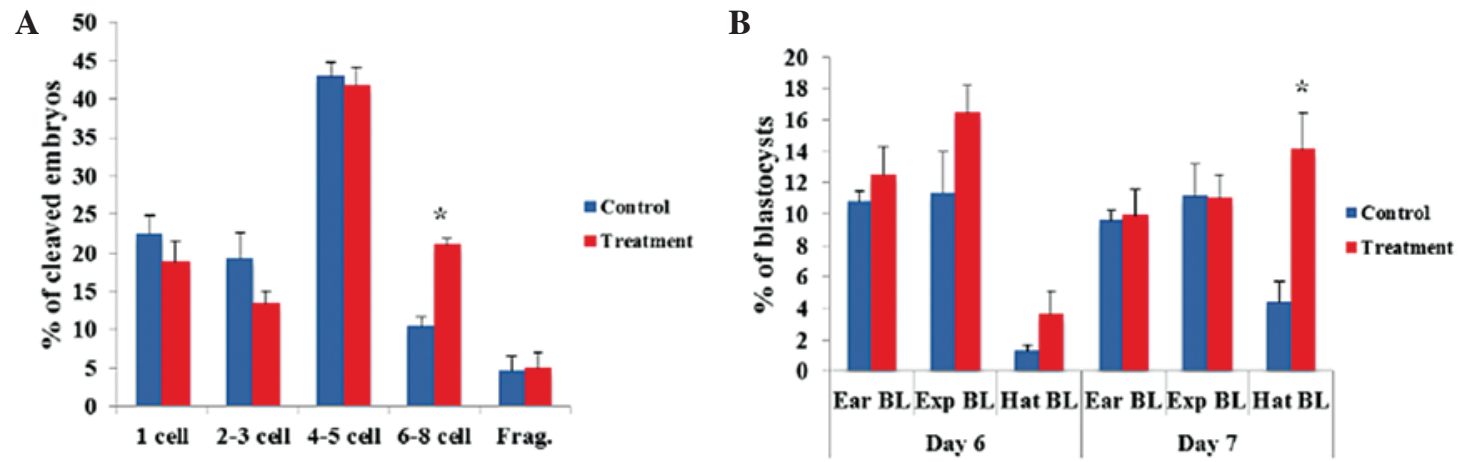

Figure 2. Effects of the novel system on cleavage and blastocyst patterns after in vitro fertilization. (A) Cleavage pattern at day 2 after PA. (B) Blastocyst pattern after PA. The data are expressed as the mean \pm standard error of the mean of three replicates ("P<0.05). PA, parthenogenetic activation; BL, blastocyst; Ear, early; Exp, expanded; Hat, hatched.

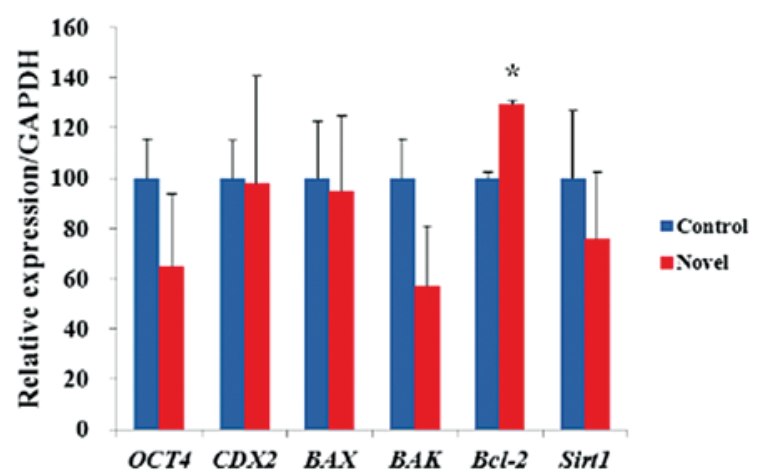

Figure 3. mRNA expression levels of $O C T 4, C D X 2, B A X, B A K, B c l-2$ and Sirtl in blastocysts following parthenogenetic activation following novel in vitro maturation system. The data are expressed as the mean \pm standard error of the mean of three replicates ( $\mathrm{P}=0.067)$.

The blastocyst formation rates were significantly greater $(\mathrm{P}<0.05)$ in the novel system $(54.5 \pm 1.8 \%)$ compared to those in the control system $(43.4 \pm 1.2 \%)$ in PA (Table II). The total numbers of blastocysts also tended to be greater $(\mathrm{P}<0.05)$ in the novel system (55.1 \pm 2.0$)$ compared to those in the control system (45.6 2.0$)$. In the IVF experiment, the blastocyst formation rate and total number of blastocysts were significantly greater $(\mathrm{P}<0.06)$ in the novel system $(36.9 \pm 3.3 \%$ and $78.9 \pm 6.8$, respectively) compared to those in the control system

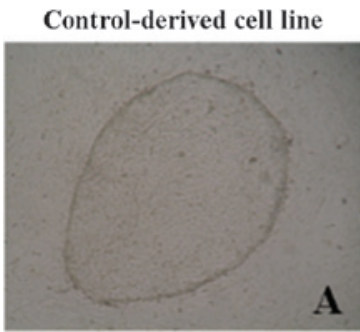

Novel system-derived cell line

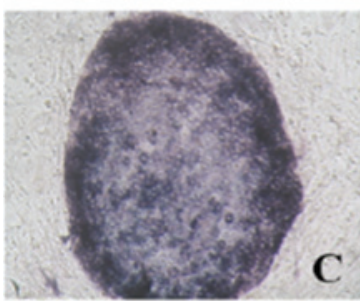

B
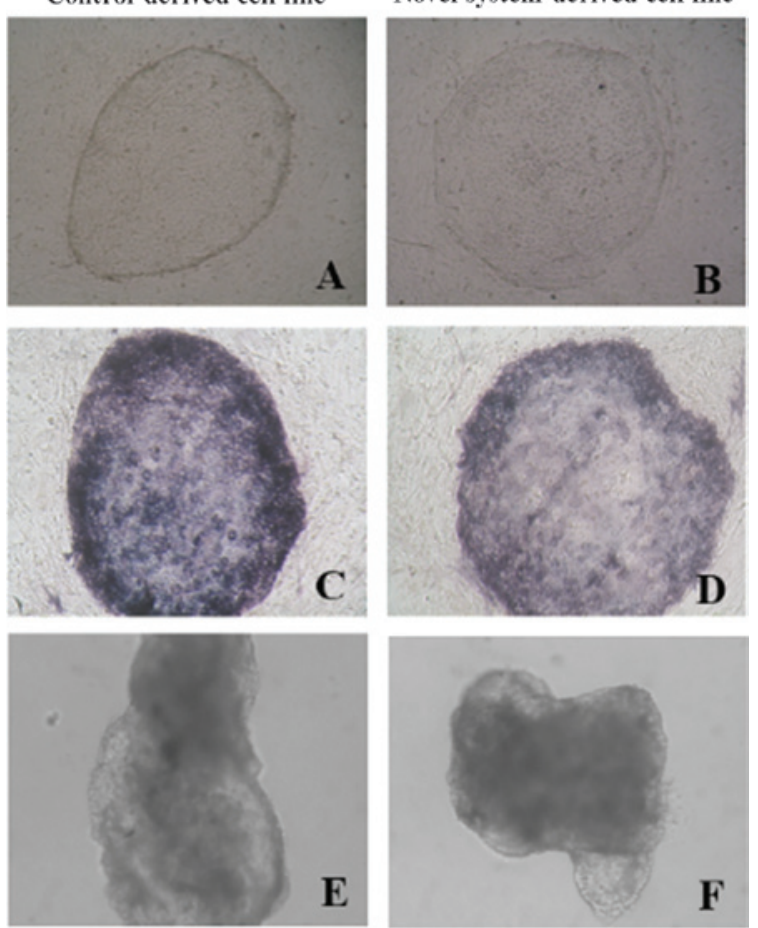

$\mathbf{E}$

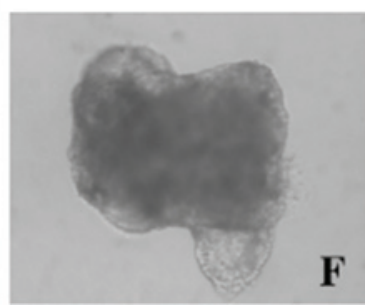

Figure 4. Derivation of putative pESC lines from blastocysts following parthenogenetic activation. (A and B) Typical morphology of putative pESCs; (C and D) alkaline phosphatase activity analysis; (E and F) embryoid body formation (magnification, $\mathrm{x} 50$ ). pESC, porcine embryonic stem cell. 
Table IV. Effects of the novel system on the attachment rate of porcine blastocysts.

\begin{tabular}{lccccc}
\hline & & \multicolumn{3}{c}{ Blastocysts attached, $\mathrm{n}(\%)$} & \\
\cline { 3 - 4 } IVP & Group & Trial no. 1 & Trial no. 2 & Trial no. 3 & Average (mean \pm SEM) \\
\hline PA & Control & $2 / 10(20.0)$ & $4 / 21(19.0)$ & $2 / 16(12.5)$ & $17.2 \pm 2.4$ \\
& Novel system & $5 / 14(35.7)$ & $6 / 21(28.6)$ & $6 / 27(22.2)$ & $28.8 \pm 3.9^{\mathrm{a}}$ \\
IVF & Control & $3 / 15(20.0)$ & $1 / 21(7.7)$ & - & $13.9 \pm 8.7$ \\
& Novel system & $10 / 18(55.6)$ & $1 / 7(14.3)$ & - & $35.0 \pm 29.2$ \\
\hline
\end{tabular}

${ }^{\mathrm{a}} \mathrm{P}=0.062$. IVF, in vitro fertilization; $\mathrm{PA}$, parthenogenetic activation; SEM, standard error of the mean; IVP, in vitro production.

Table V. Effects of the novel system on the colonization rate of porcine blastocysts.

\begin{tabular}{lcccc}
\hline & & \multicolumn{2}{c}{ No. $(\%)$ of blastocyst colonized } & \\
\cline { 3 - 4 } IVP & Group & Trial no. 1 & Trial no. 2 & Average (mean \pm SEM) \\
\hline PA & Control & $0 / 10(0)$ & $1 / 21(4.8)$ & $2.4 \pm 3.4$ \\
& Novel system & $4 / 14(21.4)$ & $1 / 21(4.8)$ & $13.1 \pm 11.7$ \\
IVF & Control & $0 / 15(0)$ & $1 / 7(14.3)$ & $7.2 \pm 10.1$ \\
& Novel system & $5 / 18(27.8)$ & $1 / 12(7.7)$ & $17.8 \pm 14.2$ \\
\hline
\end{tabular}

IVF, in vitro fertilization; PA, parthenogenetic activation; SEM, standard error of the mean; IVP, in vitro production.

Table VI. Association between the quality and attachment efficiency of in vitro fertilization blastocysts.

\begin{tabular}{lllllcc}
\hline & \multicolumn{5}{c}{ Blastocysts attached, $\mathrm{n}(\%)$} \\
\cline { 2 - 5 } Group & Trial no. 1 & Trial no. 2 & Trial no. 3 & Trial no. 4 & Trial no. 5 & Average (mean \pm SEM) \\
\hline Early blastocysts & $0 / 6(0)$ & $0 / 3(0)$ & $0 / 5(0)$ & $1 / 5(20.0)$ & - & $5.0 \pm 5.0^{\mathrm{a}}$ \\
Expanding blastocysts & $1 / 2(50.0)$ & $1 / 2(50.0)$ & $2 / 5(20.0)$ & $4 / 7(57.1)$ & $4 / 4(100)$ & $55.4 \pm 12.9^{\mathrm{b}}$ \\
Hatched blastocysts & $2 / 3(66.7)$ & $2 / 3(66.7)$ & $1 / 1(100)$ & $4 / 5(80.0)$ & - & $78.4 \pm 7.9^{\mathrm{b}}$ \\
\hline
\end{tabular}

${ }^{a, b}$ Values with different superscripts within a column differ significantly $(\mathrm{P}<0.05)$. SEM, standard error of the mean.

(26.2 $\pm 2.9 \%$ and 58.5 \pm 7.2 , respectively) (Table III). Regarding the cleavage pattern, there were significantly more 6- to 8-cell PA embryos and fewer 2- to 3-cell PA embryos in the novel system compared to the control system (Fig. 1A). However, no significant differences were observed in the cleavage patterns of 4- to 5-cell PA embryos. Regarding the blastocyst formation patterns on days 6 and 7, the number of hatched PA blastocysts was significantly $(\mathrm{P}<0.05)$ greater in the novel system than that in the control system (Fig. 1B). However, there were no significant differences in the numbers of early and expanding PA blastocysts. In the IVF experiment, there were significantly more 6- to 8-cell IVF embryos produced by the novel system compared to the control system (Fig. 2A). The hatched IVF blastocyst formation rates on day 7 were significantly higher in the novel system than those in the control system $(\mathrm{P}<0.05)$ (Fig. 2B).
To examine the expression of pluripotency- and apoptosis-associated genes, the mRNA expression levels of Oct4, Cdx2, Bax, Bak, Bcl-2 and Sirt1 in blastocysts from each system were examined (Fig. 3). The blastocysts derived from the novel system showed significantly $(\mathrm{P}<0.067)$ higher mRNA expression levels of $\mathrm{Bcl}-2$ compared to those from the control system. No significant differences were observed for the other transcripts.

Effect of the novel system on the attachment and outgrowth of blastocysts. As it is difficult to isolate ICM cells from intact porcine blastocysts produced in vitro, whole blastocysts were plated directly onto mouse embryonic fibroblasts. Following plating, the attachment rates were higher in blastocysts produced by the novel system $(28.8 \pm 3.9 \%$ in PA and $35.0 \pm 29.2 \%$ in IVF) compared to those in the control system $(17.2 \pm 2.4 \%$ in PA and 


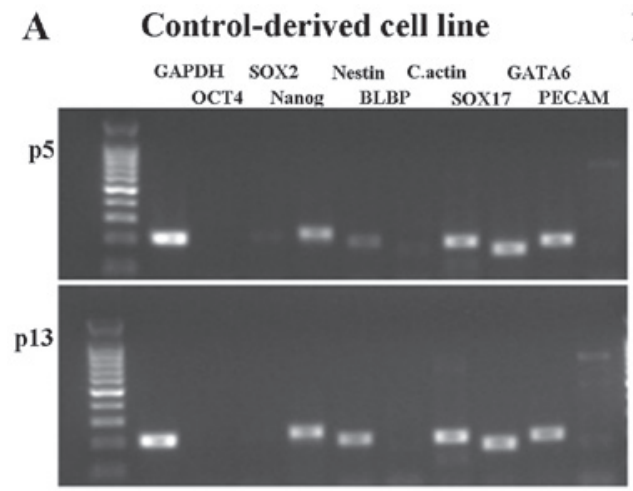

B Novel system-derived cell line GAPDH SOX2 Nestin C.actin GATA6 OCT4 Nanog BLBP SOX17 PECAM

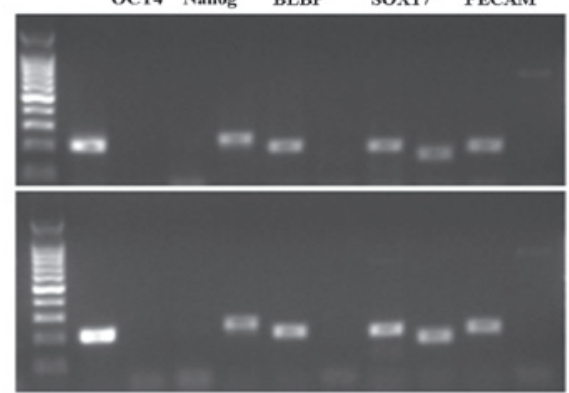

Figure 5. Reverse transcription-polymerase chain reaction analysis of pESCs. (A) Control system-derived pESC line. (B) Novel system-derived pESC line. GAPDH, OCT4, SOX2, Nanog, NESTIN, BLBP, C.actin, SOX17, GATA6 and PECAM were determined. pESC, porcine embryonic stem cell.

$13.9 \pm 3.9 \%$ in IVF) (Table IV). Furthermore, the colonization rate was higher in the novel system $(13.1 \pm 11.7 \%$ in PA and $17.8 \pm 14.2 \%$ in IVF) (Table V). Two putative pESC lines were derived from PA blastocysts using this novel system and one putative pESC line using the control system. The association between blastocyst quality and attachment efficiency was also analyzed. The numbers of expanding and hatched blastocysts $(55.4 \pm 12.9 \%$ and $78.4 \pm 7.9 \%$, respectively) were significantly greater than those of early blastocysts $(5.0 \pm 5.0 \%)$ (Table VI).

Generation and characterization of porcine pluripotent cell lines. Putative pESC lines were derived from PA embryos created by the novel and control systems. For characterization, various parameters were compared between putative pESC lines from PA embryos derived by the two systems, including typical morphology, AP activity analysis, EB formation and gene expression analysis (OCT4, SOX2, Nanog, NESTIN, BLBP, C.actin, SOX17, GATA6 and $P E C A M)$. All of the cell lines showed similar primary colonies with typical morphology and AP activity, as shown in Fig. 4A-D. The differentiation potentials of these cell lines into EBs were subsequently assessed. As shown in Fig. 4E and $\mathrm{F}$, the two cell lines showed the potential to undergo EB formation following five days of culture. When EBs were cultured onto plates coated with $0.1 \%$ gelatin, a variety of differentiated cells were observed after 2 weeks (data not shown). The expression of Nanog was confirmed in the two cell lines, whereas OCT4 and SOX2 were weakly expressed or not expressed at all (Fig. 5). The three genes known to be involved in differentiation (ectoderm markers NESTIN and $B L B P$; mesoderm marker C.actin; endoderm markers SOX17 and $G A T A 6$ ) were expressed in all cell lines.

\section{Discussion}

Blastocyst quality is one of the most important factors in implantation as well as in pregnancy as is indicated by the presence of distinct and large ICMs in high-quality blastocysts vs. poor-quality blastocysts $(25,26)$. For the establishment of ESCs from the ICM of expanded and hatched blastocysts in an in vitro system, initial blastocyst quality is crucial. The present study established a novel system using a modified culture medium treated with resveratrol, $\mathrm{pGM}-\mathrm{CSF}$ and $\beta$-ME, which improved blastocyst quality and subsequently enhanced the colonization rates of putative pESCs.

Several studies have attempted to enhance the quality of blastocysts in an in vitro system in IVM as well as IVC. According to a previous study by our group, treatment with 2.0 $\mu \mathrm{M}$ resveratrol during IVM improved the developmental potentials of PA and IVF porcine embryos by increasing intracellular glutathione levels, decreasing reactive oxygen species (ROS) and regulating gene expression during oocyte maturation due to the anti-oxidative effect of resveratrol (27). Treatment with pGM-CSF in the IVC medium also improved the developmental potential of porcine IVF embryos (28). In addition, the supplementation of IVC medium with $\beta$-ME was able to increase the developmental competence of porcine PA embryos (29). $\beta$-ME was also able to increase intracellular glutathione levels and reduce damage to the embryo caused by ROS, thus improving embryo development. The present study confirmed the positive combination effect of the above regents, showing that the novel system, by adding RES during IVM and RES, pGM-CSF, $\beta$-ME during IVC, produced more blastocysts with higher quality in PA and IVF embryos.

Furthermore, the novel system produced embryos with significantly higher expression levels of $B c l-2$ mRNA when compared with the control system. $\mathrm{Bcl}-2$ is well known to inhibit apoptosis in oocytes and embryos, while Bax a is pro-apoptotic gene (30). During the development of the early embryo, apoptosis can cause embryonic damage, including embryo arrest and developmental failure (31). In in vitro conditions, environmental stresses such as oxidative stress can also lead to apoptosis $(32,33)$. Therefore, the expression levels of anti-apoptotic genes suggested that the DNA damage occurring under in vitro conditions was significantly reduced in the novel system.

In vivo-derived blastocysts have markedly higher attachment and colony outgrowth rates than their in vitro-derived counterparts, which show an indistinct ICM in most of the embryos. Thus, most pESC lines have been established from in vivo-derived embryos (34). As shown by the results of the present study, due to the beneficial effects of the novel system, the embryos demonstrated better attachment rates and primary colony formation competence than control embryos. In human ESC derivation, blastocysts with a blastocoel size equal to or larger than half of the embryo volume had a higher rate 
of establishing ESC cell lines (35). In the present study, the expanding and hatched blastocysts showed a significantly higher attachment rate than blastocysts at an early stage, which was expected. As the novel system produced significant more hatched blastocysts at day 7 compared to the control system, a have a greater number of opportunities was available to establish putative $\mathrm{pESC}$ cell lines from in vitro-derived porcine embryos.

Putative pESCs from PA embryos derived by the novel system showed certain pluripotent characteristics, including alkaline phosphatase activity, embryoid body formation and Nanog expression. However, the low or absent expression of Oct4 and Sox2 along with the expression of three germ layer markers (Nestin, C.actin, Sox17 and Gata6) showed that these cell lines lost a certain amount of their pluripotency and may have been partially differentiated. In a recent study on putative pESC derivation, Oct4 and Nanog expression were detected (36), and Oct4, Nanog and Sox 2 expression was reported in another study (37). The pluripotent gene expression profile may have been affected by the different culture conditions. Therefore, it is presumed that the differences in gene expression observed in the present study are due to the different culture conditions and that this reflects the myriad of difficulties faced in the derivation of porcine ESCs. Thus, further studies are required.

In conclusion, the novel system using RES during IVM and RES, $\beta$-ME, pGM-CSF during IVC improved the quality of blastocysts and increased the derivation efficiency of putative pESC cell lines from in vitro-derived porcine embryos. Therefore, the present study suggested that this novel system in combination with techniques for establishing ESCs provides a more efficient approach to produce bona fide $\mathrm{pESC}$ as compared with traditional systems. The method established in the present study will help improve in vitro systems for producing porcine embryos as well as stem cell research on domestic animals.

\section{Acknowledgements}

This study was supported, in part, by a grant from the Cooperative Research Program for Agriculture Science \& Technology Development (no. PJ011288), the Rural Development Administration and the National Research Foundation of Korea Grant funded by the Korean Government (nos. NRF-2012R1A1A4A01004885, NRF-2013R1A2A2A040 08751).

\section{References}

1. Thomson JA, Itskovitz-Eldor J, Shapiro SS, et al: Embryonic stem cell lines derived from human blastocysts. Science 282: 1145-1147, 1998.

2. Evans MJ and Kaufman MH: Establishment in culture of pluripotential cells from mouse embryos. Nature 292: 154-156, 1981.

3. Handyside A, Hooper Ml, Kaufman MH and Wilmut I: Towards the isolation of embryonal stem cell lines from the sheep. Roux's Arch Dev Biol 196: 185-190, 1987.

4. Doetschman T, Williams P and Maeda N: Establishment of hamster blastocyst-derived embryonic stem (ES) cells. Dev Biol 127: 224-227, 1988.

5. Sukoyan MA, Vatolin SY, Golubitsa AN, Zhelezova AI, Semenova LA and Serov OL: Embryonic stem cells derived from morulae, inner cell mass and blastocysts of mink: comparisons of their pluripotencies. Mol Reprod Dev 36: 148-158, 1993.
6. Graves KH and Moreadith RW: Derivation and characterization of putative pluripotential embryonic stem cells from preimplantation rabbit embryos. Mol Reprod Dev 36: 424-433, 1993.

7. Talbot NC, Rexroad CE Jr, Pursel VG, Powell AM and Nel ND: Culturing the epiblast cells of the pig blastocyst. In Vitro Cell Dev Biol Anim 29: 543-554, 1993.

8. First NL, Sims MM, Park SP and Kent-First MJ: Systems for production of calves from cultured bovine embryonic cells. Reprod Fertil Dev 6: 553-562, 1994.

9. Ouhibi N, Sullivan NF, English J, Colledge WH, Evans MJ and Clarke NJ: Initial culture behaviour of rat blastocysts on selected feeder cell lines. Mol Reprod Dev 40: 311-324, 1995.

10. Saito S, Ugai H, Sawai K, et al: Isolation of embryonic stem-like cells from equine blastocysts and their differentiation in vitro. FEBS Lett 531: 389-396, 2002.

11. Li P, Tong C, Mehrian-Shai R, et al: Germline competent embryonic stem cells derived from rat blastocysts. Cell 135: 1299-1310, 2008

12. Buehr M, Meek S, Blair K, et al: Capture of authentic embryonic stem cells from rat blastocysts. Cell 135: 1287-1298, 2008.

13. Lunney JK: Advances in swine biomedical model genomics. Int J Biol Sci 3: 179-184, 2007.

14. Rui R, Qiu Y, Hu Y and Fan B: Establishment of porcine transgenic embryonic germ cell lines expressing enhanced green fluorescent protein. Theriogenology 65: 713-720, 2006.

15. Evans MJ, Notarianni E, Laurie S and Moor RM: Derivation and preliminary characterization of pluripotent cell lines from porcine and bovine blastocysts. Theriogenology 33: 125-128, 1990.

16. Vackova I, Ungrova A and Lopes F: Putative embryonic stem cell lines from pig embryos. J Reprod Dev 53: 1137-1149, 2007.

17. Miyoshi K, Taguchi Y, Sendai Y, Hoshi H and Sato E: Establishment of a porcine cell line from in vitro-produced blastocysts and transfer of the cells into enucleated oocytes. Biol Reprod 62: 1640-1646, 2000.

18. Procházka R, Petlach $M$, Nagyová $E$ and Němcová L: Effect of epidermal growth factor-like peptides on pig cumulus cell expansion, oocyte maturation and acquisition of developmental competence in vitro: comparison with gonadotropins. Reproduction 141: 425-435, 2011.

19. Funahashi H, Cantley TC, Stumpf TT, Terlouw SL and Day BN: In vitro development of in vitro-matured porcine oocytes following chemical activation or in vitro fertilization. Biol Reprod 50: 1072-1077, 1994.

20. Funahashi H, Kim NH, Stumpf TT, Cantley TC and Day BN: Presence of organic osmolytes in maturation medium enhances cytoplasmic maturation of porcine oocytes. Biol Reprod 54: 1412-1419, 1996.

21. Yoshida M, Ishigaki K, Nagai T, Chikyu M and Pursel VG: Glutathione concentration during maturation and after fertilization in pig oocytes: relevance to the ability of oocytes to form male pronucleus. Biol Reprod 49: 89-94, 1993.

22. Yoshioka K, Suzuki C and Onishi A: Defined system for in vitro production of porcine embryos using a single basic medium. J Reprod Dev 54: 208-213, 2008.

23. Nagashima H, Hiruma K, Saito H, et al: Production of live piglets following cryopreservation of embryos derived from in vitro-matured oocytes. Biol Reprod 76: 900-905, 2007.

24. Yoshioka K, Suzuki C, Tanaka A, Anas IM and Iwamura S: Birth of piglets derived from porcine zygotes cultured in a chemically defined medium. Biol Reprod 66: 112-119, 2002.

25. Dokras A, Sargent IL and Barlow DH: Human blastocyst grading: an indicator of developmental potential? Hum Reprod 8: 2119-2127, 1993.

26. Richter KS, Harris DC, Daneshmand ST and Shapiro BS: Quantitative grading of a human blastocyst: optimal inner cell mass size and shape. Fertil Steril 76: 1157-1167, 2001.

27. Kwak SS, Cheong SA, Jeon Y, et al: The effects of resveratrol on porcine oocyte in vitro maturation and subsequent embryonic development after parthenogenetic activation and in vitro fertilization. Theriogenology 78: 86-101, 2012.

28. Kwak SS, Jeung SH, Biswas D, Jeon YB and Hyun SH: Effects of porcine granulocyte-macrophage colony-stimulating factor on porcine in vitro-fertilized embryos. Theriogenology 77: 1186-1197, 2012.

29. Yuh HS, Yu DH, Shin MJ, et al: The effects of various antioxidants on the development of parthenogenetic porcine embryos. In Vitro Cell Dev Biol Anim 46: 148-154, 2010.

30. Zinkel S, Gross A and Yang E: BCL2 family in DNA damage and cell cycle control. Cell Death Differ 13: 1351-1359, 2006. 
31. Betts DH and King WA: Genetic regulation of embryo death and senescence. Theriogenology 55: 171-191, 2001.

32. Simon HU, Haj-Yehia A and Levi-Schaffer F: Role of reactive oxygen species (ROS) in apoptosis induction. Apoptosis 5: 415-418, 2000.

33. Stone JR and Yang S: Hydrogen peroxide: a signaling messenger. Antiox Redox Signal 8: 243-270, 2006.

34. Vackova I, Novakova Z, Krylov V, et al: Analysis of marker expression in porcine cell lines derived from blastocysts produced in vitro and in vivo. J Reprod Dev 57: 594-603, 2011.
35. Cheng EH, Chen W, Chang SY, et al: Blastocoel volume is related to successful establishment of human embryonic stem cell lines. Reprod Biomed Online 17: 436-444, 2008.

36. Brevini T, Cillo F and Gandolfi F: 168 Establishment and molecular characterization of pig parthenogenetic embryonic stem cells. Fertil Dev 17: 235-235, 2004.

37. Blomberg LA, Schreier LL and Talbot NC: Expression analysis of pluripotency factors in the undifferentiated porcine inner cell mass and epiblast during in vitro culture. Mol Reprod Dev 75: 450-463, 2008 